\title{
Desarrollo rural: hacia una visión compleja
}

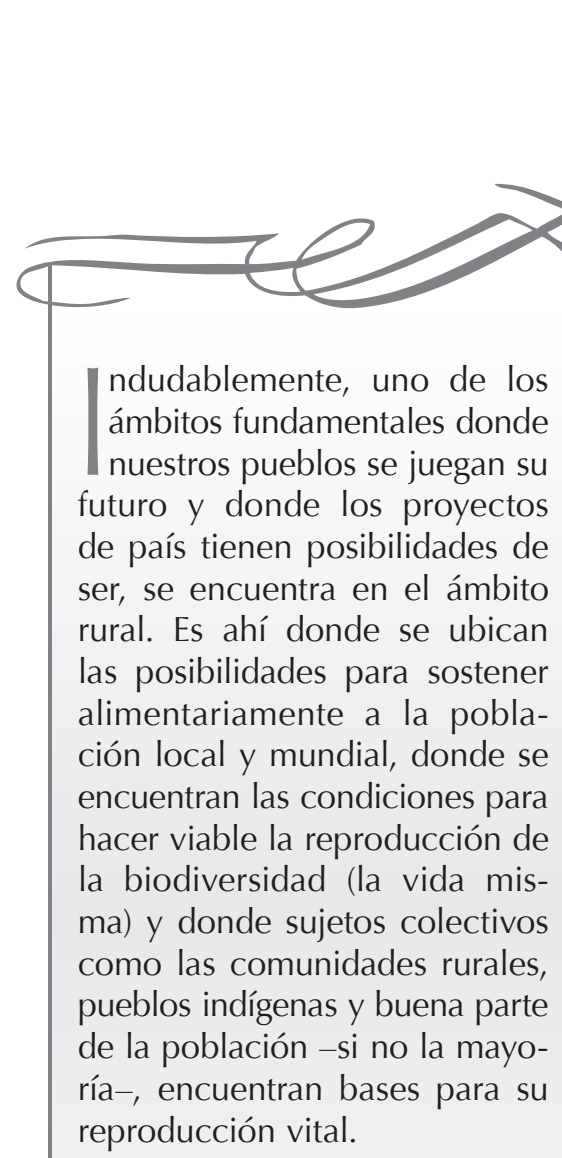

En este marco, con este artículo se pretende aportar al debate desde el cuestionamiento a las visiones del desarrollo rural imperantes en nuestros contextos. Para el efecto, no

Mario Sosa Velásquez ${ }^{1}$

se hará un repaso de cada una de ellas. Se recuperará, eso sí, un conjunto de elementos que nos permitan observar sus posibilidades y limitaciones en contextos como los nuestros. Es decir, antes que cuestionarlos en orientación prescriptiva, la intención es problematizarlos desde un acercamiento a las principales dinámicas fundamentales en el área rural, tanto relativas al modelo de acumulación de capital actual como a los efectos que genera en las formas de acción colectiva y la construcción social del territorio. Sólo desde ahí podremos generar un diálogo entre actores, experiencias y visiones, trascendiendo las sistematizaciones y evaluaciones a proyectos y programas de desarrollo específicos y nuestras lógicas con relación a lo que suele ser planteado como 
viable. Para concluir, me atreveré a sugerir algunos desafíos que considero importantes en el debate para gestar un desarrollo rural o territorial alternativo.

\section{De las visiones del desarrollo}

Es indudable que en el contexto actual, complementaria y contradictoriamente, se siguen aplicando visiones y políticas de desarrollo rural orientadas al asistencialismo irracional (como la transferencia de fertilizantes químicos, semillas transgénicas y "ayudas monetarias") que se constituyen en limitados compensadores sociales a los impactos del modelo de acumulación de capital, además de insertarse en sus lógicas. También se siguen implementando visiones productivistas y extractivistas que, orientadas a la demanda internacional, persiguen mejorar la productividad de procesos y, además, son promovidas como sinónimo de desarrollo. Estas serían las visiones más burdas que se ofertan especialmente desde actores empresariales e instituciones públicas de gobiernos de derecha, principalmente, aunque también de gobiernos que pueden ser catalogados como progresistas y de izquierda que, aun cuando presentan otras orientaciones, suelen justificar el extractivismo como parte de sus políticas. En contextos como Guatemala, son visiones correspondientes a intereses del capital dominante de procedencia local y transnacional, y en buena medida alejadas de la búsqueda del bien común.

Desde ahí se plantean actividades extractivas de distinto tipo (minería, hidroeléctricas, expansión y producción de monocultivos como palma, azúcar, soja) como motores de desarrollo. Desde ahí se propone la necesidad de mejorar las condiciones de inversión, la certeza jurídica y la seguridad, así como avanzar en la flexibilidad laboral y el abaratamiento de los costos de producción (como la energía) para garantizar que la actividad productiva genere los empleos necesarios para disminuir la pobreza.

También se encuentran visiones que recuperan de forma fragmentada u orientadas a la complementariedad de intervenciones orientadas a generar condiciones para el desarrollo rural. Así, se conocen propuestas como la agricultura ampliada. Otras propuestas combinan la perspectiva de impulsar los ejes productivo e institucional en un espacio rural determinado, planteando la necesidad de la competitividad y la sustentabilidad ligada a mercados dinámicos a los cuales debiera tenerse acceso. Se propone, asimismo, la articulación a partir del logro de la concertación de actores locales, entre estos y con actores externos. En estas perspectivas cercanas, también se plantea la integración de actores económicos, el mercado y las políticas públicas 
como necesidad para la generación de sinergias que impacten el desarrollo rural o territorial. $Y$ en el plano de la subjetividad, se propone la creación de relaciones de confianza y de credibilidad entre los agentes convocados y convocantes a gestar el desarrollo. Estas propuestas, no obstante el salto cualitativo en su formulación, generalmente son operadas en instituciones y organizaciones no gubernamentales de forma fragmentada, paralela e, inclusive, articuladas a las lógicas de acumulación de capital.

Como un ejemplo de visiones que intentan acoplar las dinámicas de acumulación dominantes con la economía campesina, se plantea la competitividad sistémica, de país, que requiere trascender lo empresarial e incluir a la economía campesina minifundista, haciéndola trascender de la auto subsistencia hacia la producción excedentaria capaz de insertarse en mercados externos a través de la innovación de los actores y su adecuación a dichos mercados. En este caso, como sucede en planteamientos que persiguen abrirle algunos cauces al desarrollo rural, se plantea como posible la conciliación de intereses entre grandes y pequeños propietarios en la orientación de la política pública. Esto es lo que el gobierno guatemalteco del general retirado Otto Pérez ha planteado como un énfasis para tratar de disminuir la movilización campesina.
En perspectiva de las ventajas comparativas y competitivas que habría que estimular y aprovechar, se habla de la diversificación, la pluriactividad, el aglutinamiento de productores, la gestación de cadenas de valor. En otras palabras, se plantea lo multidimensional y lo multisectorial que incorpora actividades productivas agrícolas, no agrícolas, servicios y externalidades económicas, y lo inter temporal que se orientaría estratégicamente a una visión de país y el aseguramiento de la sostenibilidad.

En perspectiva territorial se plantea la identidad del territorio como un elemento de primer orden en el desarrollo, idealmente que pueda convertirse en una marca o una identidad en movimiento vinculado a la producción, comercio y/o turismo. En este marco, la necesidad de contar con infraestructura esencial y un capital social con capacidades de gestar y sostener iniciativas.

Como es usual, y aun con sus diferencias de matiz o de contenido, aparecen coincidencias, como la necesidad de una institucionalidad que geste un nuevo ordenamiento político entre territorios, entre lo rural y lo urbano, entre el nivel central y las comunidades, entre lo agrícola, los servicios y la agroindustria, que fortalezca a los gobiernos locales y las organizaciones en su capacidad y legitimidad, 
garantizando la participación en el desarrollo.

En las visiones que ven al Estado como un facilitador, gestor o rector del desarrollo, se plantea el papel que puede jugar el sector público en estas búsquedas. Aquellas visiones que buscan evadir al Estado en sus dinámicas proponen que sean los actores quienes intencionen el vínculo de gobiernos o instituciones en lo local con las dinámicas alternativas de desarrollo rural o territorial. Se habla incluso del tipo de liderazgo que debiera potenciar estas búsquedas.

Como suele suceder, estas visiones no se gestan en el discurso y en la práctica siempre de forma pura. Estas visiones y experiencias, además, se sitúan en diversas orientaciones en materia de sujetos: individuos, empresas privadas, familia rural o campesina, unidad productiva campesina, cooperativa, comunidad, territorio. Han sido, incluso, objeto de planes pilotos como las estrategias regionales de desarrollo territorial o sistemas de planificación territorial que, como en Guatemala, han sido implementados por la Secretaría de Planificación y Programación de la Presidencia, en el marco del Sistema de Consejos de Desarrollo Urbano y Rural. También han incluido iniciativas de indagación y formulación de propuestas como la del desarrollo territorial, en algunos casos haciendo énfasis, por ejemplo, en el turismo ecológico y cultural.
Cada una a su manera, además, habla de un conjunto de elementos de carácter institucional que impiden, dificultan o permitirían el desarrollo rural, tales como: el asistencialismo, la corrupción, falta de recursos financieros, las fallas de coordinación y los problemas en las mesas de concertación entre actores (estatales, locales y privados), las carencias y dificultades para la participación de las mujeres y los jóvenes, los problemas de continuidad de los procesos, la inviabilidad de sistemas productivos (como el campesino) y, por ahí insertas, las estructuras de poder a lo sumo vistas generalmente en lo local.

El desarrollo es un concepto por demás controversial, objeto de debate, cuestionamiento y deconstrucción, debido fundamentalmente a su carácter hegemónico, impuesto, unilateral, lineal, jerarquizante, excluyente, economicista, antropocéntrico, occidental, paliativo y proyectista de observar, plantearse y promover el mejoramiento de las condiciones de vida de una sociedad, en un contexto marcado por relaciones de poder tanto en el ámbito global, como regional y nacional. Un concepto hegemónico, normativo y, como diría Escobar, un principio organizador de la vida social y árbitro en última instancia del pensamiento y de la práctica, un discurso que crea un vasto aparato institucional a través del cual se despliega y por medio del cual se convierte en fuerza social real y 
efectiva (1997 y 2005) y, como afirma Quijano, un dispositivo para la conquista técnica de la naturaleza y la cultura (2002).

Estas visiones se insertan en una arena de disputas conceptuales que son parte de las argumentaciones de intereses determinados por lograr la hegemonía. Son al mismo tiempo disputas por políticas, financiamientos, "beneficiarios", territorios. De ahí emanan como visiones dominantes o subalternas $y$, por consiguiente, sus posibilidades de concreción y resultados. Con visiones que incluso, desde experiencias locales o regionales, son planteadas como "exitosas", en algunos casos, o como búsquedas que aun cuando pudieran resultar marginales encarnan la construcción de alternativa.

Es aceptable pensar que experiencias emanadas de la diversidad de estas visiones han podido lograr experiencias exitosas en ciertas condiciones, lo cual se deberá a la concurrencia de múltiples variables históricas, estructurales, sociales, productivas, etc. Incluso, en contextos y procesos como los nuestros, en las condiciones y determinaciones capitalistas que enfrentamos, podrían concebirse como iniciativas de productores, comunidades o sujetos locales alternativos, insertas en estrategias de transformación territorial o complementos en la potenciación de formas de acción política colectivas en defensa del territorio, gestación de autonomía y proyectos productivos cooperativos, por ejemplo.

Se afirma lo anterior porque en países como Guatemala, desde estas visiones, instituciones estatales, ONG, agencias de financiamiento, actores locales, han logrando gestar algunas experiencias exitosas, pero aisladas, que tienden a finalizar cuando sucumbe el financiamiento externo estatal o paraestatal, en un marco donde el Estado ha presentado poco o ningún interés para financiarlas, generar condiciones para su continuidad y convertirlas -en perspectiva capitalista- en formas de acumulación alternativas, desconcentradas y sostenidas.

Más allá -y siendo que más o menos todas las visiones se orientan a la reducción de la pobreza, al logro de la equidad, de la estabilidad política y la gobernabilidad democrática-, los resultados de múltiples iniciativas no llegan a impactar en dichas condiciones de forma estructural. Esto se evidencia en el mantenimiento de los índices de pobreza y los bajos niveles de desarrollo productivo y sostenibilidad ambiental, la existencia de mayor conflictividad agraria $y$, por consiguiente, de ingobernabilidad local y nacional. En perspectiva sistémica -y no obstante los resultados medibles en términos de proyecto y programa-, estos esfuerzos han resultado funcionales y se han insertado contradictoriamente como parte de una dinámica dominada por un 
"modelo de desarrollo" que en un entendimiento alternativo podría ser calificado como fracasado o de anti desarrollo.

\section{De las dinámicas en el área rural}

Trascendiendo las visiones y sus concreciones limitadas, asistimos a una fase de acumulación de capital que, por la vía económica, de la guerra y de políticas implementadas por los Estados, está gestando la apropiación de los recursos públicos, los bienes de la ciudadanía (como los ahorros y las viviendas) y los recursos naturales y productivos. En nuestro contexto esto se expresa como dinámica de extensión e intensificación en la apropiación por el capital transnacional y local que incluye métodos económicos y extraeconómicos.

En el área rural guatemalteca, la actual etapa de acumulación de capital se realiza articulada con un modelo que se asienta en una estructura agraria concentradora de la tierra. Según datos de 2003, el $88.3 \%$ de las fincas censales son menores a 10 manzanas y el $47.5 \%$ tiene menos de 2 manzanas; en tanto, el $0.31 \%$ de las fincas, poseedoras del $50.3 \%$ de la superficie, tienen una extensión de 10 caballerías o más (INE, 2004). Por otro lado, según datos proporcionados por el Instituto de Agricultura y Recursos Naturales (URL-IARNA, 2010: 12), la agricultura de subsistencia representa el 53\% de los productores y es la encargada de la producción del $67 \%$ de los granos básicos del país. Su característica es que produce en unidades menores de 5 manzanas.

Adicionalmente, dicha estructura agraria presenta una sostenida desigualdad en el acceso a capital para población rural, campesina e indígena, con fuerzas productivas dependientes y atrasadas $y$, en su calidad de productor renovado de materias primas, orientado y dependiente del mercado internacional. Aun cuando la agricultura genera el $13.31 \%$ del producto interno bruto (PIB) al 2011, según cifras estimadas del Banco de Guatemala, emplea cerca del $50 \%$ de la fuerza de trabajo y contribuye con más del $50 \%$ de divisas a través de las exportaciones, con lo cual mantiene un lugar fundamental en perspectiva de desarrollo nacional y una importancia fundamental en la gestación del desarrollo rural.

Dicho modelo constantemente se ve determinado por los vaivenes de la demanda internacional. Esto genera que, en su fase actual, se encuentre dinamizado por algunos ejes de acumulación, entre los cuales se resaltan tres: 1) La instalación y expansión de mega-cultivos para la producción de agro-combustibles y aceites (palma aceitera o africana, caña de azúcar, piñón), banano, hule y otros, principalmente ligados con agronegocios que avanzan territorialmente a través de la compra y 
arrendamiento de tierras para establecer sus propias plantaciones, de alianzas con terratenientes locales y el establecimiento de contratos con pequeños parcelarios campesinos, en muchos casos a través de la presión forzosa e ilícita (Alonso et al. 2011, Alonso et al. 2008 y Hurtado 2008); 2) la explotación minera, petrolera e hidroeléctrica, en manos especialmente de transnacionales interesadas en mantener y expandir la exploración y explotación; 3) los mega-proyectos, generadores de altas ganancias especialmente en el largo plazo, donde se incluye la construcción de grandes represas; carreteras como la Franja Transversal del Norte (FTN), que atraviesa el país desde Belice, pasando por los departamentos de Izabal, Alta Verapaz, El Quiché y Huehuetenango, hasta Ilegar a México; el Corredor Tecnológico de Guatemala que lo atravesaría del Océano Atlántico al Océano Pacífico. ${ }^{3}$

En este marco, los procesos de acumulación de capital y de profundización del papel asignado a Guatemala, como país productor de materias primas y proveedor de fuerza de trabajo barata, tienen como una de sus concreciones la expansión de la propiedad latifundista y la reorientación de la tierra en dirección a satisfacer la demanda de agro combustibles. Esto está generando desplazamientos poblacionales y comunitarios originados de la reapropiación de tierras en nuevas zonas de apetencia capitalista, como las tierras bajas del norte (Petén y partes de Alta Verapaz, Izabal y El Quiché), la Franja Transversal del Norte, el área de cobertura del Corredor Tecnológico de Guatemala. Sumado a la pérdida de empleo, se registra un resquebrajamiento de la economía campesina y comunitaria, y, con esto, de la producción agrícola para la auto subsistencia y el mercado local, una de las bases que históricamente ha permitido la reproducción de segmentos de población campesina e indígena y la provisión de granos básicos a la población nacional.

Esto hace parte de esa compleja realidad agraria y rural en Guatemala -que implica más allá de lo expuesto-, en la cual se registra desplazamiento de población y producción campesina, despojada y suprimida con métodos legales e ilegales, desaparición del colonato ya de por sí esclavizante, aumento del desempleo rural, la conversión de campesinos en asalariados deficitarios o en productores de palma africana a partir del establecimiento de contratos para la cesión de derechos sobre la tierra y la producción, entre otras dinámicas. Todo ello con una cauda en materia de proletarización precaria de quienes son despojados de la tierra y logran insertarse en las escasas fuentes de empleo en agro negocios y fincas; asimismo en materia de impactos directos sobre la producción de alimentos, ${ }^{4}$ la inseguridad alimentaria y nutricional, ${ }^{5}$ y la persistencia $y$ 
profundización de condiciones que reproducen pobreza y extrema pobreza, ${ }^{6}$ así como una mayor vulnerabilidad socioeconómica en el corto y mediano plazo para segmentos importantes de población rural.

Estas formas de acumulación por desposesión, utilizando un término de David Harvey (2004), se realizan en un contexto donde siguen vigentes las políticas neoliberales que permiten un régimen flexible en las relaciones económicas, la consolidación de oligopolios (como el de la caña de azúcar y la palma), el traslado de recursos financieros y obras públicas a empresas privadas, el desmantelamiento de la institucionalidad pública agrícola. Asimismo, donde las políticas estatales y de instituciones financieras internacionales dan soporte a la expansión de este tipo de capitales, incluida acciones de represión dirigidas a comunidades y organizaciones rurales y campesinas, ${ }^{7}$ en las cuales participan fuerzas de seguridad del Estado y cuerpos de seguridad al servicio de los finqueros y agro negocios.

\section{De las formas de acción colectiva}

Frente a este proceso y sus dinámicas territoriales, la respuesta de diversas formas de acción colectiva, principalmente campesinas e indígenas asentadas en los espacios locales, ha sido continuar la lucha por la tierra y la defensa del territorio como aquel ámbito de repro- ducción vital de las condiciones de existencia colectivas. Estas formas de resistencia a la profundización del modelo económico, estimulada por la agudización de las formas de acumulación de capital antes descritas, han incluido diálogos y negociaciones con instituciones estatales, denuncias, movilizaciones de carretera, toma de vías de comunicación terrestre, ocupación de tierras y, como una de las acciones principales, la realización de consultas comunitarias.

Más de 70 consultas comunitarias-municipales se han realizado desde el 2005 a la fecha, la mayor parte de las cuales se han registrado en territorios indígenas, y más del $80 \%$ se han realizado para oponerse a la minería y secundariamente a la construcción de hidroeléctricas, la extracción petrolera, el cobro excesivo por servicio eléctrico. Tales consultas han logrado generar una hegemonía contraria a los proyectos mineros e hidroeléctricos en los territorios donde se han realizado. Aproximadamente 900 mil personas han rechazado -mayoritariamente en cada consulta- los proyectos mineros e hidroeléctricos en marcha o que se prevé se implementen producto de licencias de exploración o explotación autorizadas por el Estado.

El uso de procedimientos democráticos, fundamentados en instrumentos jurídicos nacionales e internacionales, permitieron que 
pronto fueran reconocidas por su legalidad y legitimidad política. Un conjunto de organizaciones e instituciones, principalmente en el ámbito de la sociedad civil y el movimiento social, han manifestado su apoyo a las mismas, pues además de representar el sentir mayoritario, han significado prácticas vinculadas a la búsqueda de democracia participativa. Pero también, porque en su realización, además de utilizar instrumentos legales, se ha reivindicado la autonomía municipal, así como derechos colectivos -principalmente de los pueblos indígenas-, relativos a la consulta, al uso de procedimientos propios, al territorio, a la administración y manejo de sus recursos naturales (Sosa, Coor. 2009: 84). Y de lo más relevante, permitió ir gestando una articulación política con representación de pueblos que avanza a nivel regional y nacional.

No obstante, la legislación y los organismos constitucionales que han avalado tales consultas -en tanto procedimiento fundamentado en la Ley de Consejos de DesarroIlo Urbano y Rural, en el Código Municipal y en el Convenio 169 de la Organización Internacional del Trabajo (OIT)-, ${ }^{8}$ no han reconocido su carácter vinculante. Los tres gobiernos nacionales que han existido desde que inician dichas consultas en el 2005, a pesar que han aceptado el carácter legal de tales procedimientos, se han negado a convertirlos en política en los territorios donde se han efectuado, con lo cual las exploraciones y explotaciones mineras continúan vigentes. No obstante, la dirigencia indígena y no indígena vinculada con esta lucha mantiene acciones de presión en distintos organismos del Estado e instancias internacionales para lograr que su decisión sea respetada, así como la movilización en aquellos contextos donde están operando empresas mineras e hidroeléctricas.

Estas acciones de resistencia colectiva constituyen, en el contexto actual, uno de los productos del modelo de acumulación de capital y una de las manifestaciones de la histórica contradicción entre capital y trabajo. Pero dicho enfrentamiento es más complejo, especialmente porque en tales acciones intervienen otras variables como la étnica e, íntimamente, la construcción social del territorio.

Es por ello que entender dicha resistencia requiere una aproximación al territorio en tanto categoría teórica, al mismo tiempo que epistemológica, ${ }^{9}$ una de las claves para explicar las búsquedas y dinámicas orientadas a controlar el territorio, es decir, por lograr gobernabilidad -otra categoría de primer ordenpara la acumulación de capital, por un lado, o para el mantenimiento de la apropiación social y étnica del territorio, el cual sigue y seguirá siendo el ámbito vital de existencia de sujetos colectivos como los 
pueblos indígenas y comunidades campesinas, principales actores que han estado al frente de esfuerzos por contener el impulso de los proyectos de acumulación de capital actualmente en marcha.

\section{Del territorio como matriz de reproducción vital}

La disputa por la apropiación de recursos y capacidades productivas, que hoy se registra en un país eminentemente agrícola (forestal por vocación de su suelo), rural y mayoritariamente indígena como Guatemala, está vinculada al territorio en tanto entramado donde se desarrollan procesos y dinámicas que permiten entender con mayor complejidad la reproducción vital de sujetos colectivos, así como la disputa que mantienen en contra de las dinámicas de capital que se imponen. ${ }^{10}$

Así, es en el territorio y desde el territorio, como construcción social compleja, que puede entenderse el proceso de confrontación y disputa por sus potencias, generalmente llamadas recursos desde el paradigma productivista, y desde el cual se están impulsando políticas y proyectos orientados a maximizar su expolio en manos de empresas transnacionales principalmente, las cuales hacen parte de estrategias empresariales $y_{\text {, }}$ al mismo tiempo, geoestratégicas, siendo la intervención de capitales globales y Estados con pretensiones de dominio regional.
En esta perspectiva, es importante considerar la búsqueda de apropiación del territorio regional a través de políticas globalizadoras del capital y su dominio, como el Tratado de Libre Comercio Estados Unidos, Centroamérica y República Dominicana (CAFTA por sus siglas en inglés) y el Acuerdo de Asociación entre la Unión Europea y Centroamérica (en proceso de ratificación), con los cuales se generan nuevas condiciones para el control económico, normativo y político del mercado por parte del capital transnacional y de los Estados del norte, con algunos beneficios en situación de desventaja para algunos capitales locales y con implicaciones en los procesos productivos, alimentarios, etc., territorializados, en lo regional y lo local.

Este tipo de proyectos -a los cuales habría que agregar el Corredor Tecnológico de Guatemala ${ }^{11}{ }_{-}$, relacionados con los proyectos de inversión privada e inversión público-privada que se explican por la búsqueda de aprovechar las "ventajas competitivas" del país, se han insertado en los territorios a través de estrategias empresariales: compra de tierras, ofrecimiento de beneficios económicos y sociales, convencimiento y compra de autoridades públicas locales o en la localidad, contratación de operadores ambientales para la realización de estudios de impacto ambiental, activación de gestores empresariales regionales y locales, activación de 
funcionarios nacionales y locales oficiosos y ministerios que, como el de Energía y Minas (MEM), han sido configurados para el beneficio de las empresas petroleras, mineras y productoras de electricidad, todo ello en un marco legal permisible al saqueo.

En la mayoría de casos, tales proyectos han sido percibidos en el ámbito local como engañosos con relación a sus promesas de empleo, beneficios sociales y reducción de pobreza. Y han sido la concreción de la continuidad del despojo, el desplazamiento poblacional y de nuevas afectaciones contra comunidades y pueblos rurales, campesinos e indígenas. Han resultado en generadores de conflictividad social, dañinos al ambiente y la producción local, corruptores de autoridades locales, etc. Han resultado, en general, proyectos impuestos, inserciones con lógica y práctica basadas en el paradigma productivista que se han dado en territorios con una complejidad que los confronta y cuya manifestación reactiva más evidente ha sido la resistencia social, principalmente indígena y campesina, a través de la cual se hace manifiesto un paradigma alternativo de desarrollo. Más allá, han venido a intensificar, como lo plantea Fernandes (2010: 6), las políticas de expropiación de comunidades rurales que pierden sus territorios para el capital, el cual necesita apropiarse continuamente de los territorios campesinos para su expansión, lo que se traduce en una disputa entre el capital y el campesinado.

Pero qué es lo que explica esa resistencia social que ha sido tan exitosa en la movilización, aunque no todavía en el objetivo de suspensión de dichos proyectos. Una respuesta importante se encuentra en el carácter de los territorios que están siendo objeto de disputa. Y es que el territorio, afirma Jara (2009), es un nido que abriga realidades cambiantes, que no son un simple agregado de elementos o cosas separadas $-y$ menos simples recursos- sino, retomando a F. Kapra, una construcción multidimensional, indivisible y compleja red de interconexiones (En Jara, 2009: 29). En ese nido, los elementos de la naturaleza (tierras, aguas, flora, fauna, recursos naturales, paisajes), como diversidad biológica y ambiental, se funden en relaciones siempre sinérgicas que se hilan en niveles históricos y profundos de la existencia con memorias colectivas, construcciones simbólicas (significativas, puestas en acción), comportamientos, hábitos, sistemas y formas productivas, tecnologías, arreglos institucionales, redes y estructuras sociales, sueños de futuro. Al mismo tiempo, esa complejidad del territorio pasa a constituirse en un elemento activo que influye en la estructuración de la sociedad.

Es desde esta perspectiva que el territorio no puede entenderse sino como una construcción social en 
donde sujetos locales-regionales, en este caso los pueblos indígenas y comunidades rurales y campesinas, han sido de sus principales articuladores. Esto es fundamental en el entendimiento del territorio y su defensa, debido a que la actividad espacial de dichos actores, la relación histórica con sus territorios, se ha dado a través de su organización social, que no solamente es productora de territorio, sino también un resultado de éste.

Contrario a lo que sucede con los proyectos extractivos, que ven al territorio como simples recursos, oportunidades y obstáculos cuando encuentran resistencias a sus propósitos, el territorio, visto desde lo local y desde su interior, es objeto de representación diferenciada por parte de los sujetos-actores territoriales, especialmente de aquéllos correspondientes a pueblos indígenas. De tal manera que éstos le atribuyen características, potencias y significados. Así, los territorios serán representaciones étnicas que trascienden lo cultural y que incluyen otras dimensiones que hacen parte de la integralidad con la cual son observados, definidos, ordenados, historizados, sacralizados, apropiados y proyectados por dichos pueblos. ${ }^{12}$ Tales representaciones, entonces, plasman los intereses de los sujetos que observan al territorio como propio, y lo hacen en los procesos de apropiación; así, estas representaciones articulan prácticas y relaciones, y vinculan economía, política, sociedad y cultura en el proceso y dinámica social territorializada, lo que es decir, en relación con el territorio.

Las representaciones del territorio son producto y productoras de relaciones y prácticas sociales territoriales, en este caso de defensa, siendo que el territorio pasa a ser parte de la identidad de los pueblos indígenas, una identidad donde el territorio es parte consustancial a dicho sujeto, en donde el territorio es pertenencia al mismo tiempo que se pertenece al territorio. Así lo plantea Mendizabal cuando afirma que los territorios se vinculan con los procesos de configuración de identidades colectivas, al ser el escenario donde éstas se realizan y el espacio que los grupos reclaman para sí y frente a los otros, aludiendo a las raíces más profundas que le dan vida al sentimiento de su ser colectivo, anclado a la historia de un lugar (2007: 57). El territorio, entonces, resulta en parte del imaginario y proyección del yo colectivo, y por ello es parte de la cohesión del pueblo indígena que se lo apropia a partir de formas de propiedad o usufructo colectivo y que lo defiende frente a las amenazas de despojo, tal y como son los proyectos extractivos. $^{13}$

Pero además de ser una construcción y una representación social, y étnica en el caso que nos ocupa, es necesario considerar que dicho proceso de configuración del terri- 
torio pasa por la apropiación que los diversos actores hacen del mismo. Y ese proceso de apropiación no es solamente un apoderamiento del mismo, como simple ejercicio en el ámbito de la economía y la política, sino una acción que al mismo tiempo es objetiva y subjetiva. ${ }^{14}$ Es decir, es la apropiación mítica, social, política que realiza un grupo social que se distingue de otros, como diría Bonnemaison, por prácticas espaciales propias (En Offman y Salmerón, 2006: 22 y 23) que tienen como punto de partida el valor que le asignan al territorio, sea éste instrumental (por ejemplo, referido a sus potencialidades económicas, geopolíticas) o cultural (en la dimensión simbólico-expresiva), que lleva a la colectividad a mejorarlo, transformarlo y enriquecerlo (Ver Giménez, 1996: 10).

De tal manera que la apropiación puede ser un ejercicio y aplicación de mecanismos procedentes de mitos que recuperan el origen ligado a la tierra y al territorio, de sacralización a través de ritos, de festividades, costumbres y tradiciones, de reconocimiento de mojones, de ciclos vitales de producción o de reproducción social, de reivindicaciones y resistencia, así como de discursos y estrategias políticas. ${ }^{15}$

Y es esta dinámica de apropiación del territorio, de estrategias y prácticas, de formas de acción colectiva, lo que genera territorialidad o territorialidades. Eso es así puesto que la territorialidad no es solamente el ámbito de relación y reproducción, la necesidad de espacio de seguridad, identidad y estímulo como afirma Borja (1998: 406) y el sentido de pertenencia, de integración, de relación íntima con el territorio. Es, asimismo, el resultado de la apropiación social del espacio, de su contenido, en donde juegan un papel importante lo significativo y los procesos de construcción de identidades territoriales que permiten y generan la organización y estructuración social, el surgimiento de normas y negociaciones a escala territorial, que ordenan las relaciones, que conciben el futuro compartido y la construcción de proyecto común al interior del territorio ubicado por el sujeto colectivo. Como diría Leff (2000 y 2006), es el locus de las demandas y los reclamos de la gente para reconstruir sus mundos de vida. ${ }^{16} \mathrm{O}$ en el planteamiento de Arturo Escobar, es el espacio de apropiación efectiva del ecosistema, es decir, aquellos espacios que la comunidad utiliza para satisfacer sus necesidades y para su desarrollo social y cultural; encarna el proyecto de vida de la comunidad (Escobar 1999: 263).

En ese sentido, el territorio es resultado de un proceso de territorialización que implica un dominio (económico y político, territorio estrictamente funcional para la reproducción vital) y una apropiación (simbólica y cultural, lo territorial 
significativo) de los espacios por los grupos humanos (Haesbaert, 2004 y 2007): "Es el espacio apropiado por una determinada relación social que lo produce y lo mantiene a partir de una forma de poder" (Fernandes, 2005: 276, traducción propia), de ejercicio de poder, y a partir del desarrollo de una estrategia determinada para controlarlo. Es resultado, asimismo, de luchas por su soberanía, a veces como "simples" resistencias y otras como discursos y prácticas autonómicas que se logran establecer en luchas impulsadas por sujetos colectivos, como las comunidades rurales y campesinas y pueblos indígenas que funden, por ejemplo, lo étnico y lo ambiental, ${ }^{17}$ que asignan un carácter étnico al territorio, lo que es decir, lo conciben como una espacio de lucha por lo propio y frente a poderes del capital y del Estado que pretenden apodérarselo. ${ }^{18}$

\section{A manera de conclusión}

Más allá de las limitaciones en materia de impacto que han tenido las distintas visiones del desarrollo imperantes, evidentes en las condiciones de pobreza, lo que intento proponer es una perspectiva más amplia y compleja en el impulso de estrategias que buscan aportar al desarrollo territorial.

Por un lado, es imposible sustraerse de aquellos procesos y dinámicas de orden capitalista que determinan las posibilidades de iniciativas específicas; asimismo del papel estratégico que sigue junado el Estado como dispositivo e instrumento de poder que apuntala un modelo de acumulación que es sinonimo de antidesarrollo. En este sentido, pensar en el desarrollo pasa por plantearse el problema de los sujetos del desarrollo y de la necesidad que articulen un proyecto alternativo a nivel nacional en coherencia con lo territorial, que geste lo alternativo en materia económica y política, e inclusive civilizatoria.

Por otro lado, desde la búsqueda del desarrollo terriorial es fundamental plantearse qué entendemos por desarrollo y por territorio. Sólo desde ahí, tendremos la posibilidad de cuestionar las posibilidades y limitaciones de nuestras visiones $y$, por consiguiente, de nuestras estrategias. Gestarlas, entonces, desde la complejidad que implica tanto el desarrollo como el territorio, para que nuestras acciones se orienten a desatar dinámicas y procesos territoriales en los cuales resulta relevante-nuevamente- el tema de los sujetos territoriales del desarrollo. $Y$ aquí no hablo de todos los sujetos del desarrollo. Hablo de los sujetos que debieran ser nuestra prioridad: aquéllos procedentes de la marginalidad, de la exclusión, etc. que insertos en relaciones conflictivas, con nuestro apoyo y sin sustituirles, encuentren mejores condiciones y capacidades para potenciar sus posiblidades partiendo de sus propias concepciones y estrategias autodefinidas. 
Y esto implica una nueva mirada de entender que tiene como punto de partida la relación dialógica a establecer con tales sujetos. Nos iría mejor si ponemos en diálogo nuestras visiones con aquéllas planteadas por los sujetos del desarrollo, un diálgo que geste el encuentro de saberes y propósitos, que potencien y articulen las oposiciones a un modelo de acumulación impuesto que nos lleva al despeñadero.
Es esencial plantearse aportar a las visiones de los sujetos del desarrollo que tienen la posibilidad de desarrollarse y gestarse como alternativas necesarias, aun cuando en apariencia parecieran poco viables en nuestras perspectivas estrechas, fragmentadas, tecnócratas, basadas en la urgencia de resultados y gestadas desde fuera de tales sujetos. Estoy planteando, entonces, un replanteamiento epistemológico y político de nuestras apuestas, con impactos en nuestras visiones y estrategias.

\section{Bibliografía}

os Alonso-Fradejas, Alberto (2010). "Capitalismo agrario y dominación a inicios del siglo XXI: Contexto y roles de actores clave en Guatemala". En Territorios, No. 5 (Guatemala: IDEAR-CONGCOOP) pp. 91-113.

os Alonso-Fradejas, Alberto, José Luis Caal Hub y Teresita Chinchilla Miranda (2011). Plantaciones agroindustriales, dominación y despojo indígena-campesino en la Guatemala del siglo XXI (Guatemala: IDEAR, CONGCOOP).

os Batres, Alexis (2011). "Auge de la palma africana crea oportunidades y riesgos". elPeriódico (Guatemala), 25 de agosto de 2011. Versión electrónica en http://www.elperiodico.com.gt/es/20110825/economia/200003/

os Borja, Rodrigo 1998 (1977). Enciclopedia de política (México DF: Fondo de Cultura Económica).

os Escobar, Arturo (2005). "El 'postdesarrollo' como concepto y práctica social". En Daniel Mato (coord.), Políticas de economía, ambiente y sociedad en tiempos de globalización. Caracas: Facultad de Ciencias Económicas y Sociales, Universidad Central de Venezuela, pp. 17-31. de Antropología e Historia y Centro de Estudios de la Realidad Colombiana). ment". En International Social Science Journal, Vol. 49, Issue 154, pp. 497-515. MA: UNESCO. Traducido del inglés. 
os Fernandes, Bernardo Mançano (2010). Territorios en disputa: campesinos y agrobusiness. Versión electrónica en http://www.landaction.org/IMG/ pdf/Bernardo_halifax_esp.pdf

(2005). "Movimentos socioterritoriais e movimentos socioespaciais. Contribuição teórica para uma leitura geográfica dos movimentos sociais". En OSAL, Observatorio Social de América Latina, No. 16 (Buenos Aires: CLACSO).

os Giménez, Gilberto (1996). "Territorio y cultura". En Estudios sobre las culturas contemporáneas (México) Época II, Vol II, Núm. 4.

os Godelier, Maurice (1989). Lo ideal y lo material (Madrid: Editorial Taurus).

os Haesbaert, Rogério (2004.) O mito da Desterritorializaçao. Do "fim dos territórios" à multiterritorialidade (Rio de Janeiro: Editorial Bertrand).

(2007). "Identidades Territoriais: entre a multiterritorialidade e a reclusão territorial (ou: do hibridismo cultural à essencialização das identidades)". En Haebaert, R. Identidades e territórios: questões e olhares contemporâneos (Rio de Janeiro: ACCES Editora).

os Harvey, David (2004). "El nuevo imperialismo: acumulación por desposesión". En Socialist Register (Buenos Aires: CLACSO). Versión electrónica en http://bibliotecavirtual.clacso.org.arg/ar/libros/social/Harvey.pdf

os Hurtado, Laura (2008). Dinámicas agrarias y reproducción campesina en la globalización. El caso de Alta Verapaz (Guatemala: F\&G Editores)

os Hoffmann, Odile (2007). "Identidad-espacio: relaciones ambiguas". En Estraga Iguíniz, Margarita y Pascal Labazée (Coord). Globalización y localidad: espacios, actores, movilidades e identidades (México: Publicaciones de la Casa Chata, CIESAS-IRD).

os Instituto Nacional de Estadística (2011). Encuesta Nacional de Condiciones de Vida (Guatemala: INE).

$\cos$

(2004). IV Censo Nacional Agropecuario.

Tomo I: características generales de productoras y productores agropecuarios (Guatemala).

os Jara, Carlos (2009). "Reflexiones sobre la teoría de los campos mórficos y el desarrollo rural sostenible". En CIDES-UMSA Desarrollo territorial y desarrollo rural. Enfoques de desarrollo territorial y desarrollo rural (Bolivia: Plural Editores). 
os Leff, Enrique (2006). Aventuras de la epistemología ambiental: de la articulación de las ciencias al diálogo de saberes (México: Siglo XXI Editores). naturaleza y la construcción local de la racionalidad ambiental". En Nueva Sociedad, No. 175 (Caracas).

os Leff, Enrique, coord. (2000). La complejidad ambiental (México: Siglo XXI editores).

os Mendizabal, Sergio (2007). El encantamiento de la realidad. Conocimientos mayas en prácticas sociales de la vida cotidiana. (Guatemala: DIGEBI e ILE, URL, Serviprensa).

os Offman, Odile y Fernando I. Salmerón Castro, Coord. (2006). Nueve estudios sobre el espacio: representación y formas de apropiación (México: CIESAS, IRD).

cos Quijano Valencia, Olver (2002). De sueño a pesadilla colectiva. Elementos para una crítica político-cultural del desarrollo (Colombia: Editorial Universidad del Cauca).

os Ramos Muñoz, Belinda y Mario Sosa Velásquez (2010). Consejos de desarrollo y participación ciudadana en Guatemala (1985-2009) (Guatemala: Programa de las Naciones Unidas para el Desarrollo).

os Solano, Luis (2009). "El negocio de la electricidad: transformación de la matriz energética y sus impactos". En El Observador, Año 3, No. 16 (Guatemala).

os Sosa Velásquez, Mario Enrique (2012). ¿Cómo entender el territorio? (Guatemala: URL; Editorial Cara Parens).

nabilidad local (Guatemala: URL, IARNA e INGEP). coord. (2009). Gestión ambiental y gober-

os Universidad Rafael Landívar, Instituto de Agricultura, Recursos Naturales y Ambiente (2010). Evaluación de la Seguridad Alimentaria y la Agricultura en Guatemala: Diagnóstico y Propuestas de Acción. Documento de trabajo 03-2010 (Guatemala).

\section{Notas}

* Antropólogo social, con grado de maestría. Investigador del Instituto de Investigaciones y Gerencia Política de la Universidad Rafael Landívar (URL). Es docente en el área de antropología

de la Escuela de Historia, en la Universidad de San Carlos de Guatemala, y en la Facultad de Ciencias Políticas y Sociales de la URL. Miembro del Grupo de Trabajo de CLACSO sobre 
"Desarrollo Rural: disputas territoriales, campesinos y decolonialidad".

1 A mediados del 2011, se reporta una extensión de 90 mil hectáreas sembradas con palma de aceite o africana en el país, con un crecimiento promedio de 10 mil hectáreas anuales (Batres, Alexis, 2011). Eso representaría, para el 2013, una extensión de 110 mil hectáreas.

2 En un esquema de privatización de este sector estratégico, la producción hidroeléctrica se encuentra íntimamente relacionada con el control en la distribución y servicio de energía en manos de transnacionales -como Energuate (antes Gas Natural Fenosa, procedente de capitales ubicados en Europa)-, altamente generadoras de resistencia social por los altos cobros que realizan principalmente en comunidades rurales, campesinas e indígenas. Entre los proyectos más grandes en este sector, de reciente construcción o en proceso, se encuentran: Xalalá, con una capacidad instalada de 181 MW, Renace II con de 163 MW y la Hidro-Xacbal con capacidad de producir hasta 94MW, los cuales son de las transnacionales Grupo Multi Inversiones, Housing and Construction Holding Co. Ltd (Shikun u'Binui) y la Grupo Terra de Honduras, respectivamente (Solano, 2009). Estos y otros proyectos, entre los cuales se incluyen aquéllos en búsqueda de financiamiento y que suman en total 145 , forman parte del Sistema de Integración Energética para Centroamérica y Panamá (SIEPAC), que se encuentra integrando el Proyecto Mesoamérica (antes Plan Puebla Panamá), plan regional que se orientaría a la provisión de energía a los principales centros industriales y urbanos con creciente demanda, ubicados principalmente en el norte del continente.
Para ampliar, ver también Alonso et al. (2011), Hurtado (2008) y la revista El Observador, Nos. 13 al 19, 28 y 29, en www.aselobs.org

4 Complementariamente y de carácter estratégico en perspectiva geoeconómica y geopolítica, se encuentra operando el tratado de "libre comercio" (TLCAUSA) que entre otras consecuencias abrió el mercado local al ingreso de granos básicos procedentes de Estados Unidos, generando una baja sustancial en la producción de alimentos para la auto-subsistencia y el aprovisionamiento de los mercados locales y regionales, a tal punto que la Organización de las Naciones Unidas para la Agricultura y la Alimentación y el Programa Mundial de Alimentos (2010) confirman a Guatemala como un país deficitario en la producción de alimentos para consumo interno. El país es hoy un importador neto de maíz, fríjol negro, arroz, carne de res, carne de pollo, carne de cerdo, huevos de gallina y leche.

5 La población infantil en condición de desnutrición crónica alcanza el 49.8\%, según los últimos datos a febrero de 2012, situándose el país en primer lugar con este flagelo en América Latina y el sexto lugar a nivel mundial. En áreas de poblamiento indígena, la desnutrición crónica alcanza un 82\% (Diario de Centro América, 13/02/2012).

6 Según la Encuesta Nacional de Condiciones de Vida -ENCOVI 2011- (INE: 2011), el 54\% de la población guatemalteca vive en condición de pobreza, tres puntos porcentuales más que en el 2006. El $13.33 \%$ de dicha población vive en pobreza extrema. El Índice de Desarrollo Humano es de 0,574, por debajo de la media de América Latina que se encuentra en el 0,731; además, ubica al país en el lugar 131 de los 187 
países para los que se disponen de datos comparables.

7 Hurtado, refiriéndose a las transformaciones que se suceden en Alta Verapaz, al norte del país, concluye en su estudio: "Los resultados a los que asistimos en la actualidad en el agro de esta región son -en gran medida- fruto de la voluntad expresa del Estado, al promover, impulsar o permitir tales dinámicas con el concurso de sus políticas [... políticas que ] derivan de directrices generales de las instituciones financieras internacionales, del Banco Mundial y del Banco Interamericano de Desarrollo principalmente, y fueron impulsadas con financiamiento y apoyo de estos organismos" (Hurtado, 2008: 386 y 387$)$.

8 La Ley de Consejos de Desarrollo Urbano y Rural (Decreto legislativo 112002) instituye un sistema de participación ciudadana para la planificación del desarrollo. A pesar de las incoherencias en su implementación por sucesivos gobiernos, las escalas comunitaria y municipal de este sistema han funcionado por la voluntad política de algunos gobiernos municipales y principalmente por el protagonismo de la ciudadanía que ha logrado avances en su desarrollo, específicamente en la realización de asambleas y consultas en contra de actividades extractivas, tanto en el ámbito comunitario como municipal (Ver Ramos y Sosa, 2010). Lo mismo sucede con el Código Municipal, el cual se ha hecho efectivo a partir de retomar de éste, la facultad ciudadana y del gobierno municipal para la realización de cabildos o consultas a los vecinos en asuntos de trascendencia del municipio $\mathrm{y}$ en tanto han afectado derechos e intereses de las comunidades indígenas o sus autoridades propias, así como la garantía para la aplicación de usos y costumbres indígenas en su concreción. Asimismo, con el Convenio 169 de la OIT, ratificado por Guatemala en 1996 -en el cual se reconoce a los Pueblos Indígenas como sujetos de derechos, entre ellos el de decidir sus propias prioridades en materia de desarrollo, el de ser sujetos protagónicos de su propio desarrollo, en la formulación, aplicación y evaluación de planes y programas que se implementen a nivel regional o nacional- manda al gobierno nacional a consultar a los pueblos interesados, a través de sus instituciones representativas, cada vez que se prevean leyes y políticas que puedan afectarles directamente.

9 Indudablemente también a los territorios concretos, en tanto en estos se dilucida y se comprueba empíricamente la contradicción entre capital y trabajo, pero también otras relaciones, construcciones, dinámicas y procesos socio históricos que explican la variabilidad con que se manifiesta tal contradicción y que se ligan estrechamente con procesos étnicos, por ejemplo.

10 En el texto, ¿cómo entender el territorio? El territorio es entendido como un tejido complejo de espacios, lugares y tiempos específicos y circunscritos dinámicamente, que articula una matriz multidimensional de condiciones y circunstancias, de dinámicas y procesos, de sistemas abiertos y duraderos de configuración, representación, reproducción y apropiación de las potencias, energías y elementos objetivos y subjetivos en compleja relación, que funciona como una estructura estructurante de las percepciones, acciones y relaciones de los sujetos y sus actores en la corta y larga duración. El territorio, esa compleja red de contenidos y formas, de condicionamientos objetivos y subjetivos interrelacionados, que 
-consciente o inconscientemente en los diversos actores sociales- estructuran procesos, dinámicas y prácticas sociales. (Sosa, 2012: 116-117)

11 El Corredor Tecnológico de Guatemala es gestionado desde el 2003. Se preveía que la obra iniciara en 2012 y fuera concluida en el 2015 , pero ha sufrido retrasos. La inversión anunciada es de US $\$ 12$ mil millones, procedente de capital transnacional y secundariamente de capital local. Dicho proyecto tendría una longitud de $308 \mathrm{~km}$ y un ancho de 140 metros, que comprende 100 metros de vía para paso de ferrocarriles de carga, 20 metros de autopista y 20 metros para un poliducto interoceánico, que permitirá el traslado de contenedores, productos derivados del petróleo, gas y otro tipo de mercancías, entre los océanos Atlántico y Pacífico, paralelo a la frontera con Honduras y El Salvador. Indudablemente, de llevarse a cabo, constituye un enclave para el comercio mundial y la acumulación de capital en perspectiva transnacional, bajo un esquema de propiedad privada o concesionada por los municipios involucrados. Asimismo bajo criterios de competitividad y aprovechamiento de economías de escala en el proceso de producción y transporte, siendo que será construido un centro logístico en cada uno de los litorales, los que incluirán: puerto concentrador de contenedores, zonas francas para empresas globalizadas, aeropuerto internacional de carga, servicios complementarios y de apoyo, incluidos un conjunto de negocios de carácter turístico, comercial, financiero, industrial, entre otros. Este proyecto reconfiguraría los territorios que abarca en tanto les generaría cortes terrestres, privatizaría todos los servicios (incluidos derechos de peaje), provocaría el desplazamiento de po- blación campesina, así como unidades productivas pequeñas, vulneraría aun más las condiciones ambientales y contribuiría al aumento de la inseguridad alimentaria y nutricional al mermar la producción de alimentos.

12 Los procesos de apropiación simbólica, de entrada diferenciados entre los distintos sujetos y actores, generan condiciones para el conflicto con relación al uso del territorio, en tanto síntesis de espacio y tiempo vividos colectivamente, en la forma en que se estructura el tiempo y el espacio territorializados, que se genera -al mismo tiempo y como una relación complementaria o de confrontacióndesde lo global y desde lo local.

13 Arturo Escobar manifiesta que, para el caso de las organizaciones étnico-culturales, "el territorio es un espacio fundamental multidimensional en el que se crean y recrean las condiciones de sobrevivencia de los grupos étnicos y los valores y prácticas culturales, sociales y económicas que les son propios. La defensa del territorio es asumida en una perspectiva histórica que liga el pasado con el futuro. En el pasado, la historia de los asentamientos mantuvieron cierta autonomía, conocimientos, modos de vida, y sentidos éticos y estéticos que permitieron ciertos usos y manejo de los recursos naturales." (1999:194)

14 Esto no es contradictorio con la perspectiva de Harvey, quien afirma que "las concepciones objetivas [y yo agregaría subjetivas] de tiempo y espacio se han creado necesariamente a través de las prácticas y procesos materiales que sirven para reproducir la vida social [...]. La objetividad del tiempo y el espacio, agrega, está dada en cada caso, por las prácticas materiales de la reproducción social y, si tenemos en cuenta que estas últimas varían geográfica e histórica- 
mente, sabremos que el tiempo social y el espacio social están construidos de manera diferencial (Harvey, 2004: 228).

15 Como expresa Godelier (1989), el territorio es el espacio que una sociedad reivindica como el lugar donde sus miembros han encontrado permanentemente las condiciones y los medios materiales de su existencia y lo que reivindica al apropiarse de un territorio es el acceso, el control y el uso, tanto respecto a las realidades visibles como a las potencias invisibles que lo componen, entre las que parece estar repartido el dominio de las condiciones de su reproducción y de los recursos de que dependen.

16 Enrique Leff observa el nivel local como el lugar donde se forjan las identidades culturales, donde se expresan como una valorización social de los recursos económicos y como estrategias para la reapropiación de la naturaleza (2001: 37)

17 Leff plantea que "las poblaciones indígenas están generando nuevos derechos culturales para recuperar el control sobre su territorio como un espacio ecológico, productivo y cultural, para reapropiarse un patrimonio de recursos naturales y significados culturales. La racionalidad ambiental está siendo internalizada por nuevos actores sociales, expresándose como una demanda política que guía novedosos principios para la valorización del ambiente y para la reapropiación de la naturaleza, arraigándose en nuevos territorios y nuevas identidades" (Leff, 2001: 38-39).

18 Hoffmann concibe el territorio étnico como "espacio de emancipación y lucha por la autonomía de decisión de un colectivo social auto-adscrito a una 'identidad étnica'. En esta visión, el control territorial constituye la condición mínima para el ejercicio de un poder 'autónomo', el único medio de conseguir cierta legitimidad para construir instituciones y normas 'propias', que gocen de la aprobación 'de la comunidad"' (2007: 442). 